\title{
Macro Perspective of Industry 4.0: Factors Affecting Value Creation Modules
}

\author{
Saeed A. Mousa \\ Palestine Technical University, Tulkarm, Palestine
}

\begin{abstract}
Business needs to manage such a variety of things inside the firm or outside the business consistently. This factor affects the business in various ways. The factor which affects the business is clients, suppliers, distributors and so on. These all components are isolated from two sections full-scale environment and miniaturized scale environment. Macro perspective environment components are those external variables which are past the association's control. The problem of this study is guaranteeing a supportable evolvement of human presence in its social, ecological, and monetary measurement. So, we have to adapt test in order to outfit toward manageability. As for the method used in this study, it depends on using empirical framework to meet the interest of capital and buyer, in addition to supporting human presence in its social, ecological, monetary measurement. The paper is organised as following sections: first section is the introduction, second section is the literature review, the third section includes the research method, fourth one discusses the analysis, while the conclusion is in the fifth section.
\end{abstract}

Keywords: Industry 4.0, lead market, industrial internet, digital work

\section{Introduction}

The expression "Industry 4.0" was at first authored by the Germans. It depicts and typifies an arrangement of innovative changes in assembling and sets out needs of a clear arrangement structure with the point of keeping up the worldwide aggressiveness of German industry. It is applied in that it establishes a method for comprehension a watched wonder and institutional in that it gives the system to a scope of strategy activities recognized and bolstered by business delegates that drive an innovative work program. Industry 4.0 portrays the association of creation procedures taking into account innovation and gadgets self-governing speaking with each other along the quality chain: a model of the "sense" manufacturing plant without bounds where PC driven frameworks screen physical forms, make a virtual duplicate of the physical world and settle on decentralized choices in view of self-association instruments.

The idea assesses the expanded computerization of the assembling ventures where physical articles are consistently coordinated into the data system. Accordingly, "fabricating frameworks are vertically connected with business forms inside industrial facilities and undertakings and on a level plane associated with spatially scattered quality systems that can be overseen continuously — from the minute a request is sent directly through to outbound logistics.” These improvements make the refinement amongst industry and administrations less

Saeed A. Mousa, lecturer, Palestine Technical University, Tulkarm, Palestine.

Correspondence concerning this article should be addressed to Saeed A. Mousa, Yaffa Str. P.O. Box: 7, Kadoorie University, Tulkarm, Palestine. 
pertinent as computerized advances are associated with mechanical items and administrations into half and half items which are not one or the other products nor benefits solely. Without a doubt, both the terms "Web of Things" and "Web of Administrations" are considered components of Industry 4.0.

The external examination looks at the open doors and dangers in the environment. The inside examination concentrates on the factors which help in addressing the necessities of its real business sector. Market transforms all the time, and it doesn't rely on the kind of item that business produces; business needs to respond to the changing environment or else will lose clients (Adner \& Kapoor, 2010). The report manages the different components influencing an industry and the effect on the association. The approaches like financial, fiscal, mechanical, work and right import strategies are impacted by particular economic institutions and system towards the business partnerships.

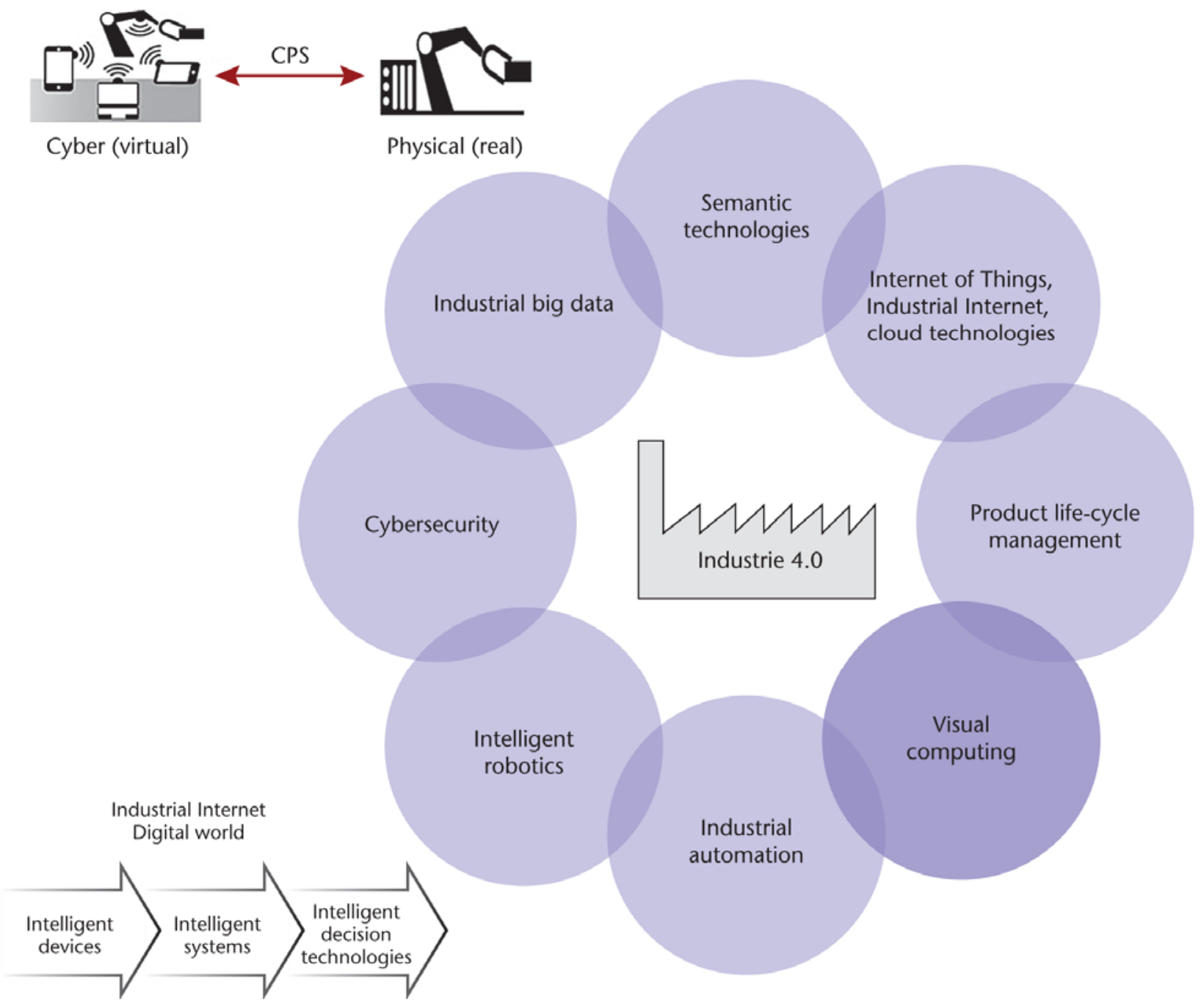

Figure 1. Industrial Internet digital world.

The United States has an industrialist blended economy, which is fuelled by rich common assets, a very much created foundation, and high efficiency. It is the biggest shipper of merchandise and second largest exporter, however, sends out per capita are moderately low. The business sector situated economy and the strong conventions in rivalry and venture have made the USA the world's pioneer in many business areas 
(Broda \& Weinstein, 2010). The United States has a stable just political system and a strong legal system. The United States has utilized expansionary financial strategy to keep the economy alive alive, prompting a significant increment in the spending shortage and a resulting downsize in its sovereign FICO assessment by one appraisal Industry 4.0. Legislators are attempting to get control over the macro perspective shortfall. However, continued advancement has not yet been made. Financing costs are at notable lows due to expansionary money related strategy, which may continue if the economy hints at proceeded with a shortcoming (Brindley, Blaschke, \& Walti, 2009).

\section{Purpose of Study}

This paper will display a best in the class audit of Industry 4.0 taking into account late advancements in examination and practice. Therefore, an outline of various open doors for feasible assembling in Industry 4.0 will be introduced. A utilization case for the retrofitting of assembling hardware as a particular open door for maintainable producing in Industry 4.0 will be exemplarily laid out. The extent of the study is to dissect how the idea of Industry 4.0 is executed and to depict the important measures to make and serve new lead markets for technologies and products.

\section{Literature Review}

Bledowski has proposed that the causes of the thought are to be found in the German management's 2006 High-Tech Strategy. A portion of the components of Industry 4.0 was recognized in Germany's modern arrangement in 2010 and in 2012 the administration made Industry 4.0 one of 10 future ventures a portion of its High-Tech Strategy. A working gathering comprising of delegates from industry, scholastics, and in 2013 distributed at last report laying out 8 needs of an Industry 4.0 methodology running from institutionalization to keep learning. The Ministry of Economics expressed the objective of cultivating exploration and development "at a precompetitive organize" and quickening the way toward moving exploratory discoveries into the advancement of attractive technologies. That this not just concerns vast partnerships turns out to be clear when the system expressly incorporates the objective of reinforcing the development force of business visionaries and SMEs by making ability communities for Industry.

The German management has subsequently organized its dedication to Industry 4.0 by setting up a stage drove by Ministries of Economy and Research uniting agents from business, science, and the exchange unions 36 . The Industry 4.0 stage has separated up its first ranges of center crosswise over five distinctive working gatherings: Reference Design; Standardization; Research and Innovation; Networked Systems Security; Lawful Environment; and Work, Education/Training. The stage issued the first report in April 2015. This report presented the utility of Industry 4.0 to the largest economy and society as one of the key angles to be further investigated later on and plot a more refined examination guide until 2030. This time, skyline demonstrates that Industry 4.0 is a highly long haul methodology, and the change it looks to cultivate is still in embryonic structure.

They should showcase items that compare to society's center and secondary values, and address the requirements of various subcultures inside a general public. In the joint environment, advertisers should know about crude materials deficiencies, expanded vitality expenses and contamination levels, and the changing part of managements in ecological security (Gentile, Spiller, \& Noci, 2007). In the mechanical field, advertisers ought to assess the quickening pace of innovative change for development, shifting R\&D spending plans, and the expanded administrative direction realized by the innovative change. Finally, in the political-legal 
environment, advertisers must work inside the many laws managing business practices and with different particular vested parties. The Keynesian economy is a hypothesis of macro perspective created by British John Maynard Keynes in the twentieth century which empowers and contends the possibility of non-effective results of macro perspectives and results in an arrangement which incorporates money related parts, for example, the financial approach to a national bank and macro perspective strategy (Shah, 2006).

\section{Methodology}

An empirical framework methodology that has been used to present the globalization is confronted by the test to meet the consistently developing overall interest for capital and buyer merchandise by all the while guaranteeing a supportable evolvement of human presence in its social, ecological, and monetary measurements. So as to adapt to this test, quality mechanical creation must be outfitted towards manageability. Right now, the mechanical value establishment in the early industrialized nations is formed by the improvement towards the fourth phase of industrialization, the purported Industry 4.0. This improvement gives colossal changes to the acknowledgment of practical assembling.

\section{Methodology Approach}

This "emperical study" depends on significant data effectively accessible on the subject and examination of significant measurable information. As the terms of reference point out, this implies there are sure constraints in such a methodology. Specifically, this implies sees, assessments or contentions exist that have not yet been advanced as classified information won't be incorporated into the input. This section comprises of factors influencing value creation modules. The finish of the study will only base on the above variables.

\section{Theoretical Framework}

A worldview Industry 4.0 will be a stage forward towards more possible mechanical quality creation. In current writing, this progression is, for the most part, portrayed as a commitment to the original measurement of manageability. The designation of assets, i.e., items, materials, vitality, and water, can be acknowledged in a more efficient manner on the premise of keen cross-connected value creation modules.

\section{Research Problem}

The present globalization is confronted by the test to meet the consistently developing overall interest for capital and buyer merchandise by all the while guaranteeing a supportable evolvement of human presence in its social, ecological, and monetary measurements. So as to adapt to this test, quality mechanical creation must be outfitted towards manageability. Right now, the mechanical value establishment in the early industrialized nations is formed by the improvement towards the fourth phase of industrialization, the purported Industry 4.0. This improvement gives colossal changes to the acknowledgment of practical assembling.

\section{Preconditions for Industry 4.0}

One key center of the survey is to distinguish the preconditions required for the effective execution of Industry 4.0. The nearness of these prerequisites, and the capacity to make such preconditions where they don't exist, differ between the Member States. Figure 2 presents a positioning of difficulties distinguished taking into account a review done in 2013.

Institutionalization of frameworks, stages, conventions, associations, and interfaces appeared is significant and a reference design to give a specialized portrayal of these models and encourage their usage to help 
business execute Industry 4.0 procedures. This won't work without a level of openness and a joint effort between organizations. Work association will need to change reflecting changes in plans of action. Complex frameworks will be dealt with the assistance of arranging and informative models. Ongoing focused control will change work substance and procedures and environment, bringing about expanded obligation and preceded with advancement required for people. This will require a purposeful exertion amongst partners with a specific end goal to be fruitful. In what manner can a typical EU lawful system to empower the digitalization of industry be created and actualized?

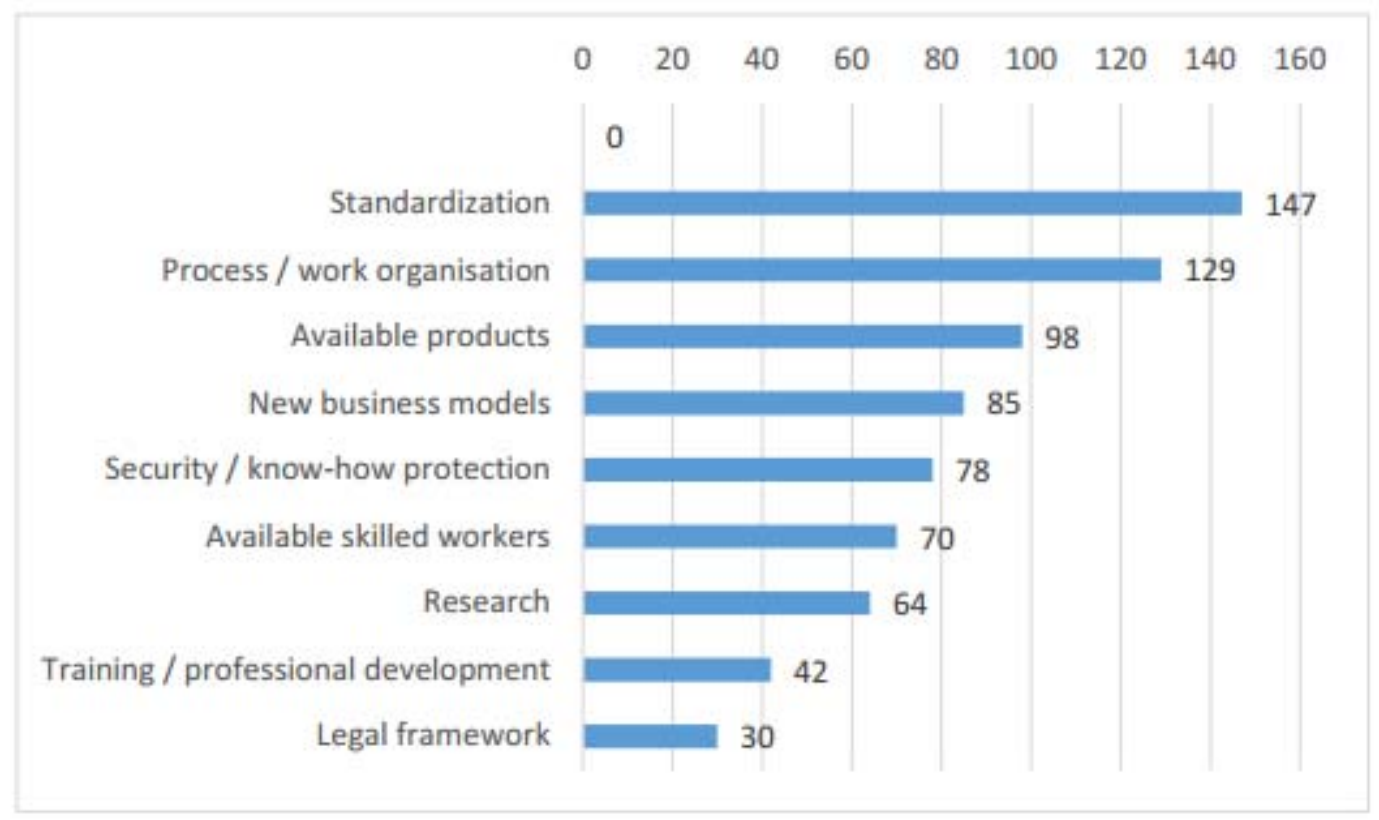

Figure 2. Prerequisites for Industry 4.0.

This is a precondition for organizations to execute Industry 4.0 in the Single Market as it would permit them to pool assets to attempt the speculations expected to coordinate their creation frameworks. The assurance of corporate information, obligation issues, and the treatment of individual information and exchange limitations will be tended to be by control. A few, for example, the consultancy Roland Berger contend that a "sober-minded" antitrust strategy taking into account ID of "modern champions" to develop opposite the US and Asia would be "useful." This would be a critical takeoff from current EU modern strategy. Be that as it may, the inverse contention can be made that remiss antitrust strategy advantage large organizations making syndications and setting gauges that advantage them-thus raising the passage hindrances for SMEs and newcomers. At long last, (open) interest in the settled and portable broadband framework for industry both inside the Member States and between them will be expanded with a specific end goal to encourage the execution of scattered generation systems (fulfillment of the Digital Single Market).

The effect of Industry 4.0 and how advantages are acknowledged will vary amongst nations and enterprises. Businesses with an abnormal state of item variations, for example, the car and sustenance and drink enterprises will profit by a higher level of adaptability through ventures with an emphasis on brilliant, for instance, semiconductors and pharmaceuticals may profit by diminished blunder rates. A few organizations are all around situated to serve new markets. The key organizations will increment in significance incorporate 
innovation suppliers, framework suppliers (distributed computing, huge information stockpiling and preparing, telecoms, SAP) and mechanical clients (e.g., Siemens, VW, or BASF). In every classification, new players which may develop or build up European economies may pick up a lead. The effect may likewise vary by organization size: new companies and small organizations may create and give downstream services and further coordinate themselves into quality chains or despite what might be expected may confront restrictive passage obstructions to taking part in the advanced change of assembling. Sway between the Member States will contract contingent upon their preparation to embrace new innovations and their general progression in assembling. Industry 4.0 may likewise advantage remote or immature districts as advances, for example, 3D printing makes customized, decentralized and neighborhood creation conceivable (expecting the pertinent pre-conditions are available).

\section{Hypothesis}

Macro perspective markets, in the event, that they have very much created assign budgetary assets proficiently among the different business ventures (Adner \& Kapoor, 2010). In figuring meaningful choices, supervisors need to consider present and future ecological open doors and dangers. Industrialists build up an original business thought with an external client base. At that point, they continue to examine the environment for circumstances and hazards and break down the outcomes in the light of Industry 4.0's assets and qualities. This investigation gives the chiefs the data to settle on the plausibility of the business thought. Oversight in recognizing open doors or dangers can prompt confused key choices and business disappointment.

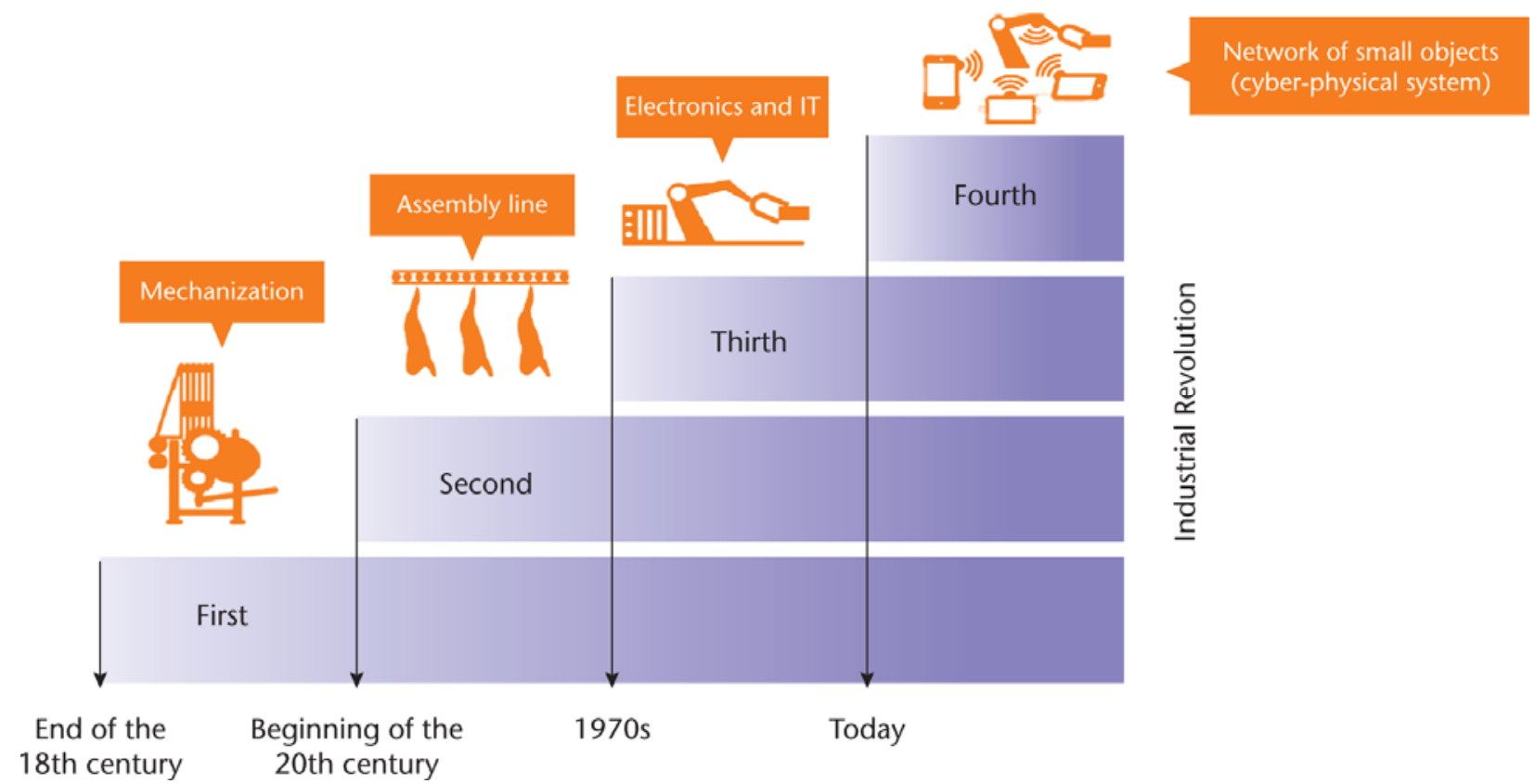

Figure 3. Phases of industrial revolutions.

\section{Lead Markets and Industry 4.0 Interpretation}

Lead market methodologies, rather than supporting an innovation push (supply) course to advancement, intend to endeavor request side open doors and location insufficiencies that debilitate entrepreneurial activities and interest in development. The point is to organize party request approaches favoring those business forms 
that lead to more development. Industry 4.0 on-screen characters then build up an Action Plan with achievable results in view of improvements in enactment and direction, open obtainment, institutionalization, marking, protected innovation administration and confirmation; and other complimentary activities that may be supplemented by more routine supply side arrangements conveyed through bolster administrations or access to back, for instance. As indicated by the Final Report of the Industry 4.0 working gathering, "Industry 4.0 holds immense potential for assembling industry in Germany. The main business sector for Industry 4.0 is Germany's residential assembling industry". The point is to shape and grow the German lead market through systems administration by organizations at proximate destinations and co-operation between organizations all the more for the most part. This will require advanced reconciliation of the diverse phases of quality chains, item life cycles, item extends and the necessary assembling frameworks.

\section{The "Dual Strategy" Success}

Support for Industry 4.0 consolidates the first market technique with the major provider system. German hardware makers are in post position to give driving answers for Industry 4.0 items. The double methodology was embraced, gone for (a) enhancing the aggressiveness of German industry generally speaking by supporting predictable reconciliation of ICT into its generation procedures and (b) expanding on German organizations' ability in inserted frameworks and computerization designing, growing new items in assembling hardware that Germany could offer on worldwide markets, and that would encourage a move to Industry 4.0 in different nations. It could be said, the methodology is both guarded (went for keeping up focused) and forceful (grow new lead markets). A case of the main supplier of advanced and arrangements activity is that of the “Autonomic for industry 4.0" launched by the German management and executed by 14 relationships from science and industry. The goal is to encourage profoundly adaptable foundations that empower the development of troublesome items. The activity distributes $€ 55$ million to 19 ventures covering human-machine communication, building models and a "speed factory" which underpin very electronic and value creation forms in the material business. Measures supported incorporate meetings, workshops, research, and reasonable exchange appearances. Results can be normal in 2017.

\section{Discussion/Conclusion}

The report recognized one specific test as the developing quality systems of endeavors that as of now work all around since SMEs regularly work exactly at a provincial level. It goes ahead to bring up that "numerous SMEs are not set up for the basic changes that Industry 4.0 will involve, either in light of the fact that they do not have the imperative master staff or due to a mindful or even suspicious state of mind towards an innovation methodology that they are still new with.” As to understand this lead market technique a key component is coordinating these SMEs into worldwide value systems in an extensive learning and innovation exchange program (e.g., through pilot applications and significant practice cases that exhibit advantages and prompt expanded copying by different SMEs thus). This would evacuate obstructions to associate with and use of CPS techniques. To empower this likewise requires quickened utilization and advancement of the mechanical foundation (e.g., fast broadband), preparing skilled laborers and creating tweaked and proficient hierarchical plans for multiple working courses of action.

The economy, the management, and the laws it makes specifically influence value creation methodologies for the business (Kotler \& Keller, 2005). Along these lines, it is vital to investigate these components in 
connection to the Leomil business environment. Firstly, the worldwide economy is a notevaluey supporter to the accomplishment of any business. Industry 4.0 that desires to investigate the global corporate sector must consider the economies of both the local and the nation in which it is extending its operations. A productive economy does not ensure accomplishment in the business but rather gives more chances to the execution of quality creation systems. Then again, a fizzled economy is well on the way to give lesser chances to value creation accordingly decreasing the probabilities of progress. It is in this way critical for an Industry 4.0 to dissect the economy before moving into the worldwide business sector.

Furthermore, it is additionally essential to note that social and macro perspective variables that influence the economy may likewise affect the accomplishment of business. For instance, savagery or war more often than not pushes the economy on a descending pattern (Gentile, Spiller, \& Noci, 2007). In this way, an Industry 4.0 may wish to pull back operations from a war-torn nation because of the impacts of the war. Furthermore, a creating nation might be the ideal spot to begin operations because of the steady development of the economy. The second variable that impacts the achievement of value creation techniques is the administration. In any nation, the administration assumes a vital part in making and actualizing laws that are relevant to the business world. For Industry 4.0s working on a global connection, it is essential to decide the pretended by the economy in settling on choices that influence Industry 4.0s and the economy overall.

\section{Future Work}

With the developing data innovations, for example, IoT, huge information, and distributed computing together with computerized reasoning advances, we trust the shrewd manufacturing plant of Industry 4.0 can be executed. The keen machines and items can convey and arrange with each other to reconfigure themselves for adaptable creation of various sorts of items. The huge information can be gathered from keen relics and exchanged to the cloud through the IWN. This empowers the framework wide input and coordination in light of huge information examination to improve framework execution. The above self-sorted out reconfiguration and enormous information based input and coordination characterize the structure and operational system of the keen production line. The savvy manufacturing plant executes the economical generation mode to adapt to the worldwide difficulties. It can prompt novel business modes and even influence our way of life. Despite the fact that the usage of brilliant production line is as yet confronting some specialized difficulties, we are strolling on the right way by at the same time applying the current advances and advancing specialized progressions. With the current advances, some application exhibits have as of now been constructed. In this way, the savvy production line and the Industry 4.0 can be executed logically, alongside the unstopped specialized progressions. Later on, we will keep on developing our model outline and concentrate on the key empowering advances.

Furthermore, environment assurance laws likewise influence worldwide business transactions. Inability to consent to such laws typically prompts inward and outside weight to close assembling plants. In synopsis, an accomplishment in the global corporate sector involves consistency with universal laws (Meral \& Dinçer, 2011). When all is said in done, a standout amongst essential variables in value creation is an Industry 4.0's business operation. The operations must be intended towards making value for the client and for every one of the partners. For instance, customers in the apparel fabricating industry value the nature of outlines and nature of articles of clothing delivered. Along these lines, to boost value creation, the business operations must concentrate on making original plans and assembling unique apparel. Taking everything into account, the day to day business operations must run easily if the Industry 4.0 is to make progress and in the end value creation. 


\section{References}

Adner, R., \& Kapoor, R. (2010). Value creation in innovation ecosystems: How the structure of technological interdependence affects firm performance in new technology generations. Strategic Management Journal, 31(3), 306-333.

Brindley, J., Blaschke, L. M., \& Walti, C. (2009). Creating effective collaborative learning groups in an online environment. The International Review of Research in Open and Distributed Learning, 10(3).

Broda, C., \& Weinstein, D. E. (2010). Product creation and destruction: Evidence and price implications. The American Macro Perspective Review, 100(3), 691-723.

Buonanno, G., Faverio, P., Pigni, F., Ravarini, A., Sciuto, D., \& Tagliavini, M. (2005). Factors affecting ERP system adoption: A comparative analysis between SMEs and large companies. Journal of Enterprise Information Management, 18(4), 384-426.

Franke, N., \& Schreier, M. (2010). Why customers value self-designed products: The importance of process effort and enjoyment. Journal of Product Innovation Management, 27(7), 1020-1031.

Gentile, C., Spiller, N., \& Noci, G. (2007). How to sustain the customer experience: An overview of experience components that co-create value with the customer. European Management Journal, 25(5), 395-410.

Gereffi, G., Humphrey, J., \& Sturgeon, T. (2005). The governance of global value chains. Review of International Political Economy, 12(1), 78-104.

Jacobides, M. G., Knudsen, T., \& Augier, M. (2006). Benefiting from innovation: Value creation, value appropriation and the role of industry architectures. Research Policy, 35(8), 1200-1221.

Kotler, P., \& KELLER, L. (2005). Kevin. Marketing Management, 12.

Lu, X. H., Huang, L. H., \& Heng, M. S. (2006). Critical success factors of inter-industry 4.0al information systems-A case study of Cisco and Xiao Tong in China. Information \& Management, 43(3), 395-408.

Meral, M. E., \& Dinçer, F. (2011). A review of the factors affecting operation and efficiency of photovoltaic based electricity generation systems. Renewable and Sustainable Energy Reviews, 15(5), 2176-2184.

Middleman, A. B., Kozinetz, C. A., Robertson, L. M., DuRant, R. H., \& Emans, S. J. (2001). The effect of late doses on the achievement of seroprotection and antibody titer levels with hepatitis B immunization among adolescents. Pediatrics, 107(5), 1065-1069.

Nemet, G. F. (2006). Beyond the learning curve: Factors influencing cost reductions in photovoltaics. Energy Policy, 34(17), 3218-3232.

Shah, S. K. (2006). Motivation, governance, and the viability of hybrid forms in open source software development. Management Science, 52(7), 1000-1014. 